\title{
Effect of Sputtering Method on Characteristics of Amorphous Ni-Nb-Zr Alloys for Glass Lenses Molding Die Materials*
}

\author{
Junpei SAKURAI**, Mitsuhiro ABE**, Masayuki ANDO**, Yuko AONO**, \\ Jiang SHENGXIAN**, Akira SHIMOKOHBE** and Seiichi HATA** \\ ** Precision and Intelligence Laboratory, Tokyo Institute of Technology \\ 4259 Nagatsutacho, Midoriku, Yokohama 226-8503, Japan \\ E-mail:sakurai.j.aa@m.titech.ac.jp
}

\begin{abstract}
We investigated the characteristics of amorphous $\mathrm{Ni}-\mathrm{Nb}-\mathrm{Zr}$ alloys for fabricating dies for molding high-precision optical glass lenses. Two amorphous $\mathrm{Ni}-\mathrm{Nb}-\mathrm{Zr}$ samples with similar compositions were prepared using carousel-type and parallel plate sputtering systems; we refer to these samples as the synthesized sample and the target sample, respectively. These two samples were evaluated and compared the desired characteristics for molding dies for optical glass lenses, namely a high mechanical strength, a high hardness, a thermally stability of amorphous state, a high oxidation resistance, a similar linear expansion coefficients to that of glass, and a high machinability. The thermal stability of amorphous state, oxidation resistance, and linear expansion coefficient did not depend on the fabrication method, whereas the mechanical properties, hardness, and machinability did. In particular, the target sample exhibited excellent mechanical strength and machinability. Finally, we fabricated a molding die made from amorphous $\mathrm{Ni}_{35} \mathrm{Nb}_{40} \mathrm{Zr}_{25}$ alloy for optical glass lenses using diffraction gratings.
\end{abstract}

Key words: Amorphous Alloy, Sputtering, Optical Glass Lens Mold, Machinability

\section{Introduction}

Recently, functional optical glass lenses with precise microstructures, such as diffractive gratings or micro lens arrays, have been the subject of active and rapid development. Currently, optical glass devices are produced using glass molding techniques with molds made of tungsten carbide ${ }^{(1),(2)}$. However, it is difficult to fabricate precise microstructures in tungsten carbide by machining processes because of significant tool wear. Moreover, since tungsten carbide is a sintered material with microparticles of tungsten carbide and Co-binder, there is a tendency for the tungsten carbide particles to drop out at the edges of parts ${ }^{(2)}$. Although many researchers have been investigating the fabrication of precision tungsten carbide molds for optical glass devices through improvements in the machining processes ${ }^{(1)}$, (2), this could take significant time.

In the meantime, researchers have also been searching for new candidate molding die materials to replace tungsten carbide. In particular, amorphous alloys are expected to be excellent candidate molding die materials for functional optical glass lenses with precise microstructures. Currently, amorphous alloys, such as electroless Ni-P platings ${ }^{(3),(4)}$, are being used industrially for molding die materials of optical plastic devices, such as pick-up lenses compatible with CD - DVD drives or optical elements for LCD or projection TVs, ${ }^{(4)}$ because they show good machinability using diamond cutting tools ${ }^{(4)-(6)}$. Some researchers, including our group, had been attempting to apply electroless Ni-P

${ }^{*}$ Received 27 July, 2010 (No. 10-0305) [DOI: 10.1299/jmmp.4.1742]

Copyright () 2010 by JSME 
platings to glass lens molding dies ${ }^{(6),(7)}$. However, molding dies made of electroless Ni-P platings are destroyed during the glass molding process, and their lifetimes are too short for industrial applications. Generally, the molding temperature of glasses is more than $700 \mathrm{~K}\left(723 \mathrm{~K}\right.$, in the case of the commonly known glass material BK7 (Shotto AG)) ${ }^{(8)}$. However, the crystallization temperature $T_{\mathrm{x}}$ of the electroless Ni-P plating is approximately $623 \mathrm{~K}$, lower than the glass molding temperature ${ }^{\left({ }^{9}\right)}$. Thus, electroless Ni-P platings crystallize during the molding process and become brittle.

In our previous studies, we have been searching for new amorphous alloys for glass lens molding die materials using a combinatorial technique ${ }^{(8),(10)-(12)}$. So far, we have investigated the properties of $\mathrm{Pt}{ }^{(8),(10)}$ and Ni-based ${ }^{(11),(12)}$ amorphous alloys for glass lens molding die materials. Amorphous $\mathrm{Ni}-\mathrm{Nb}-\mathrm{Zr}$ alloys are promising materials for fabricating molding dies for glass lenses. We used the combinatorial approach to search for suitable amorphous $\mathrm{Ni}-\mathrm{Nb}-\mathrm{Zr}$ alloys for fabricating molds for glass lenses, and we investigated the characteristics of 17 different amorphous $\mathrm{Ni}-\mathrm{Nb}-\mathrm{Zr}$ alloys ${ }^{(11),(12)}$. These samples were synthesized by carousel-type sputtering. Instead of preparing 17 different alloy targets, this method allows for the fabrication of samples with various alloy compositions by varying the radio frequency (RF) power supplied to the target of each constituent element ${ }^{(13)}$. Here, we refer to these samples as synthesized samples. Based on the results of the previous studies, we concluded that the amorphous $\mathrm{Ni}_{36} \mathrm{Nb}_{39} \mathrm{Zr}_{25}$ alloy is a suitable molding die material for glass lens molds because it has high thermal stability in the amorphous state, high mechanical strength, linear expansion coefficient similar to that of conventional glass, and good machinability.

Figure 1 shows a schematic of the process used for fabricating a glass lens molding die using an amorphous alloy. The amorphous alloy is sputter-deposited on the optical aspheric surface of a blank molding die. A portion of the amorphous alloy is then cut using a single-crystal-diamond cutting tool to form a precise mold pattern for an optical element such as a diffraction grating. In industrial fabrication processes, amorphous alloys are generally sputter-deposited using a conventional parallel-plate sputtering system with an alloy target, because such a system yields a reproducible alloy composition and higher sputtering rates than a carousel-type sputtering system. In this paper, we refer to these samples as target samples. However, there is concern that the properties of amorphous alloys are adversely affected by this fabrication method.

In this study, we compare the characteristics of the synthesized and target amorphous alloys, and demonstrate the fabrication of a molding die for glass lenses with diffraction gratings using a target amorphous $\mathrm{Ni}-\mathrm{Nb}-\mathrm{Zr}$ alloy.

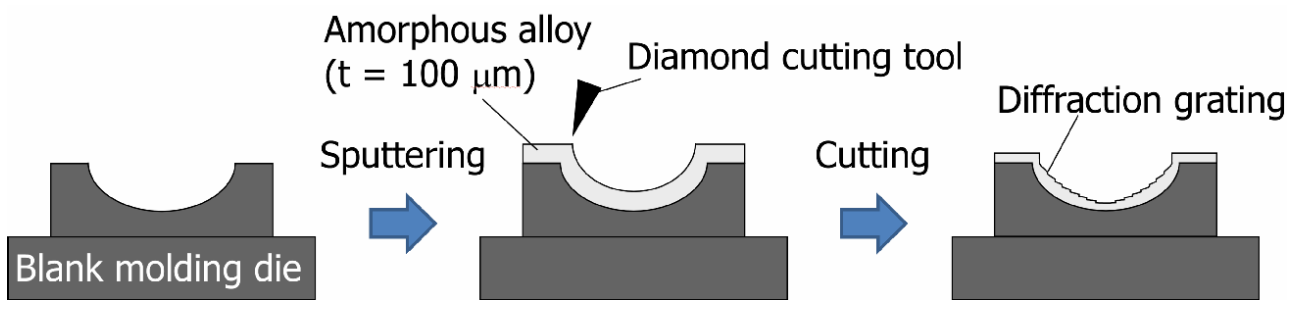

Fig. 1 Process for fabricating a molding die for glass lenses using an amorphous alloy

\section{Experimental Methods}

Amorphous $\mathrm{Ni}-\mathrm{Nb}-\mathrm{Zr}$ alloys were prepared using the carousel-type $\mathrm{RF}$ magnetron sputtering system (L-350S-C, Cannon Anelva) shown in Fig. 2. This system has a rotating substrate holder at the center of a chamber and several targets positioned around the chamber wall ${ }^{(13)}$. Two kinds of samples were fabricated using this system. Synthesized samples were fabricated by rotating the substrate holder at $50 \mathrm{rpm}$ and co-sputtering several pure metal targets on a substrate. On the other hand, this system 
could be used as a conventional parallel-plate sputtering system by fixing the substrate holder and using an alloy target. Target samples were fabricated by this method.

Table 1 shows the sputtering conditions for these two kinds of amorphous $\mathrm{Ni}-\mathrm{Nb}-\mathrm{Zr}$ samples. Both samples were deposited on $\mathrm{Al}_{2} \mathrm{O}_{3}$ substrates for measurements of their compositions, thicknesses, oxidation resistances, and machinabilities, and on $\mathrm{Cu}$ foils measurements of their mechanical strengths and linear expansion coefficients. The thicknesses of both kinds of samples were measured using a white-light interferometer (NewView 5032, Zygo) and were found to be approximately $5 \mu \mathrm{m}$. The compositions of both kinds of samples were measured by energy-dispersive X-ray fluorescence spectroscopy ( $\mu \mathrm{EDX}-1300$, Shimadzu). The synthesized sample had a composition of $\mathrm{Ni}_{36} \mathrm{Nb}_{39} \mathrm{Zr}_{25}$, whereas the target sample had a composition of $\mathrm{Ni}_{35} \mathrm{Nb}_{40} \mathrm{Zr}_{25}$ (at.\%).

The mechanical properties were measured by performing tensile tests using a thermal mechanical analyzer (TMA; TMA-60, Shimadzu) with a strain rate of $0.0017 \mathrm{~s}^{-1}$. Prior to the tensile tests, the $\mathrm{Cu}$ foils were dissolved in $\mathrm{HNO}_{2}+\mathrm{H}_{2} \mathrm{O}(1: 1)$. The samples were cut into $1 \times 7 \mathrm{~mm}^{2}$ strips using a diamond wire saw (Musashino Electron). Hardness was measured by the nanoindentation method using an atomic force microscope (SPI-3000, Seiko Instruments) equipped with a nanoindenter (Triboscope, Hysitron). Hardness tests were performed at five positions on each sample. Linear expansion coefficients were measured by performing thermal expansion tests using the TMA. The heating rate was 0.33 $\mathrm{K} / \mathrm{s}$. The measurement temperature was varied in the range 303 to $573 \mathrm{~K}$.

Both kinds of samples on $\mathrm{Al}_{2} \mathrm{O}_{3}$ substrates were annealed at $723 \mathrm{~K}$ for various times in a vacuum using an image furnace (MILA-3000, Ulvac Technology) to evaluate the thermal stability of their amorphous states and in an air using a muffle kiln (MMF-1, As One) to evaluate their oxidation resistances. The phases of the annealed samples were identified by X-ray diffraction (XRD; RINT 2200, Rigaku).

The machinabilities of the samples were evaluated by performing cutting tests with an ultra-precision diamond machining system (Nanoform 350, Precitech). Figure 3 shows a schematic of the cutting test setup. The workpiece used in the tests was a sample deposited on an $\mathrm{Al}_{2} \mathrm{O}_{3}$ substrate. The workpiece was in the workpiece holder, which was rotated at $200 \mathrm{rpm}$. The workpiece was cut in a tapered shape using a single-crystal-diamond radius

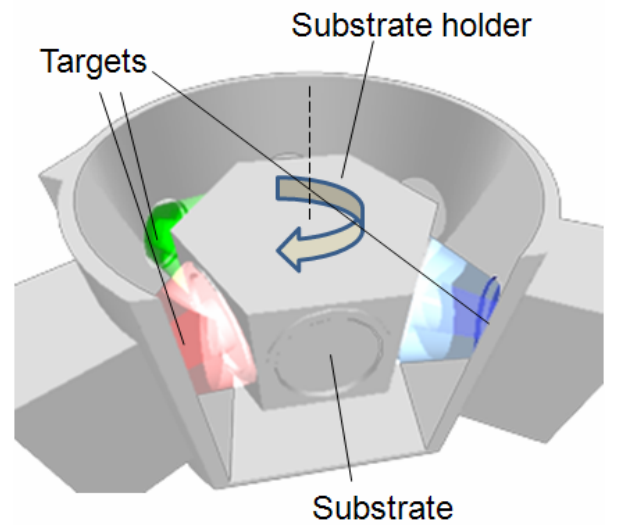

Fig. 2 Carousel-type sputtering system

Table 1 Sputtering conditions for synthesized and target $\mathrm{Ni}-\mathrm{Nb}-\mathrm{Zr}$ samples

\begin{tabular}{|c|c|c|}
\hline Samples & Synthesized samples & Target samples \\
\hline Targets & $\mathrm{Ni}(2 \mathrm{~N}$ up), Nb (3N), Zr (2N up) & $\mathrm{Ni}_{35} \mathrm{Nb}_{40} \mathrm{Zr}_{25}$ (at.\%) \\
\hline RF powers & $\mathrm{Ni}: 100, \mathrm{Nb}: 267, \mathrm{Zr}: 160 \mathrm{~W}$ & $200 \mathrm{~W}$ \\
\hline Sputtering times & $21,600 \mathrm{~s}$ & $2400 \mathrm{~s}$ \\
\hline Base pressure & \multicolumn{2}{|c|}{$<5 \times 10^{-4} \mathrm{~Pa}$} \\
\hline Ar pressure & \multicolumn{2}{|c|}{$1.0 \mathrm{~Pa}$} \\
\hline
\end{tabular}


cutting tool with a nose radius of $0.5 \mathrm{~mm}$, a rake angle of $0^{\circ}$, and a clearance angle of $5^{\circ}$. The radial feed was $1 \mu \mathrm{m} / \mathrm{rev}$, the axial feed was $1 \mathrm{~nm} / \mathrm{rev}$, and the target cutting angle $\theta_{0}(=$ cutting depth/cutting width) was $1 \mu \mathrm{m} / \mathrm{mm}$. The feed start position was $3.5 \mathrm{~mm}$ from the rotation center. The feed distance in the radial direction was $3 \mathrm{~mm}$. The cut surface was observed using the white-light interferometer. In this study, we define the removal fraction $F_{r}$ as the index of machinability, which is expressed as $\theta / \theta_{0} \times 100 \%$, where $\theta$ is the actual cutting angle.

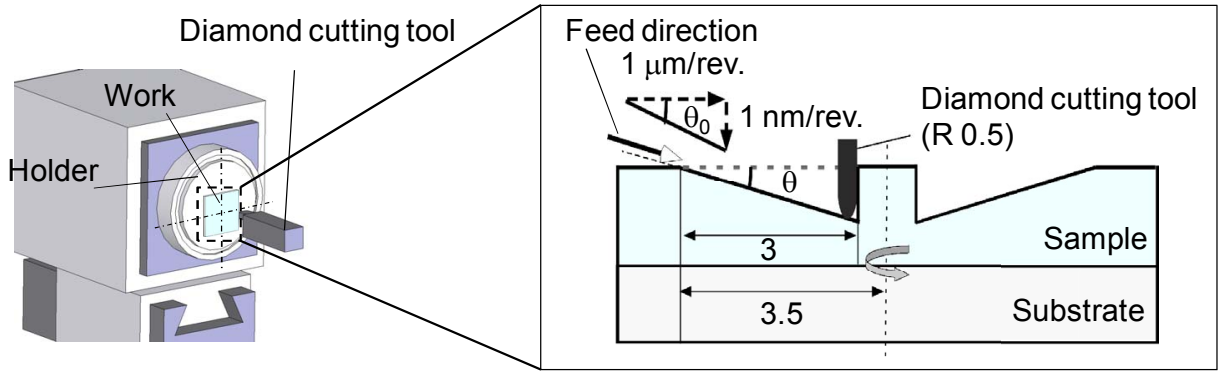

Fig. 3 Set up for the cutting tests

\section{Results and Discussion}

\subsection{Mechanical properties}

Molding die materials require a high compression strength to prevent molding dies from breaking during cooling after molding. However, since the two samples in this study were too thin to evaluate their compression strengths, we measured their tensile strength instead. The fracture stress $\sigma_{f}$ was evaluated during the tensile test; ideally, $\sigma_{f}$ should be more than $1.0 \mathrm{GPa}$.

Figure 4 shows stress-strain curves for both $\mathrm{Ni}-\mathrm{Nb}-\mathrm{Zr}$ samples. Both samples fractured during elastic deformation. The synthesized sample had a fracture stress $\sigma_{f}$ of $1.1 \mathrm{GPa}$, a fracture strain $\varepsilon_{f}$ of $1.8 \%$, and a Young's modulus $E$ of $62.0 \mathrm{GPa}$, whereas the target sample had $\sigma_{f}$ of $1.7 \mathrm{GPa}, \varepsilon_{f}$ of $2.4 \%$, and $E$ of $70.9 \mathrm{GPa}$. Both samples have sufficiently high fracture stresses (over $1.0 \mathrm{GPa}$ ) to enable them to be used as die materials for molding glass. The target sample had a higher fracture stress and strain and Young's modulus than the synthesized sample.

Molding die materials are required to have a high hardness to ensure good mold transferability. The hardness should be $8.0 \mathrm{GPa}$ or higher. The hardnesses of both samples were measured by the nanoindentation method. The synthesized and target samples had hardnesses of 8.0 and $10.0 \mathrm{GPa}$, respectively. Thus, the target sample was harder than the synthesized sample. These results demonstrate that the synthesized and target samples have different mechanical properties.

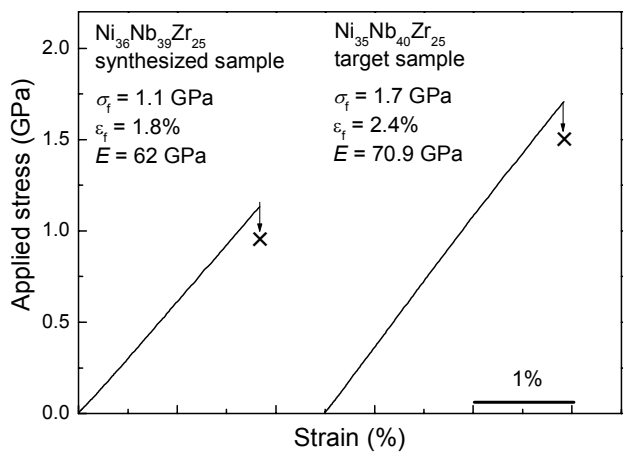

Fig. 4 Stress-strain curves of the amorphous $\mathrm{Ni}-\mathrm{Nb}-\mathrm{Zr}$ alloys 


\subsection{Linear expansion coefficients}

Molding die materials are desired to have similar linear expansion coefficients to that of glass to prevent optical glass lenses and the molding die from breaking during cooling after molding. In this study, we assumed that BK7 is used as the glass. BK7 is a popular glass for optical components. The linear expansion coefficient of BK7 is $8.3 \times 10^{-6} / \mathrm{K}$ for temperatures in the range 293 to $573 \mathrm{~K}^{(14)}$.

Figure 5 shows strain-temperature curves for thermal expansion tests of the thin-film amorphous $\mathrm{Ni}-\mathrm{Nb}-\mathrm{Zr}$ alloys. The initial stress of $10 \mathrm{MPa}$ was applied to the samples by the weight of the bottom chuck gripping the end of the samples. Both samples expanded with increasing temperature. The mean linear expansion coefficients were estimated by the method of least squares to be $8.3 \times 10^{-6} / \mathrm{K}$ for the synthesized sample and $7.9 \times 10^{-6} / \mathrm{K}$ for the target sample. Both samples had similar linear expansion coefficients to that of BK7. This result demonstrates that the linear expansion coefficient does not depend on the fabrication method.

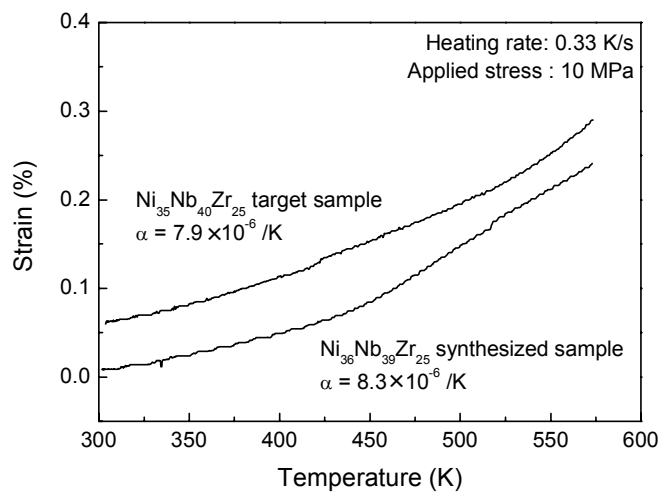

Fig. 5 Strain-temperature curves of the amorphous $\mathrm{Ni}-\mathrm{Nb}-\mathrm{Zr}$ alloys

\subsection{Thermal stabilities of amorphous state and oxidation resistances}

Molding die materials need to have high thermal stabilities at the molding temperature. Amorphous alloys require an amorphous state with a high thermal stability to prevent crystallization from occurring during molding because crystallization of the amorphous alloy might make the alloy brittle or form a rough surface. During molding of optical lenses made from BK7, the molding dies are heated at $723 \mathrm{~K}$. Consequently, we evaluated the thermal stabilities of the amorphous states of the two alloy samples at 723 $\mathrm{K}$ in vacuum. The maximum annealing time was set to $100 \mathrm{~h}$ because the target lifetime for a molding die is $100 \mathrm{~h}$; this lifetime permits 10,000 glass lenses to be fabricated from a single molding die.

Figures 6(a) and (b) show XRD profiles for synthesized $\mathrm{Ni}_{36} \mathrm{Nb}_{45} \mathrm{Zr}_{25}$ samples and target $\mathrm{Ni}_{35} \mathrm{Nb}_{40} \mathrm{Zr}_{25}$ samples annealed at $723 \mathrm{~K}$ for various times in vacuum, respectively. All the XRD profiles contain several sharp peaks corresponding to the $\mathrm{Al}_{2} \mathrm{O}_{3}$ substrate. Both annealed samples have a halo pattern due to the amorphous phase and no peaks corresponding to crystalline phases. These results indicate that both samples exhibit excellent thermal stabilities of amorphous state.

In addition, it is desirable for molding die materials to have high oxidation resistances. This is because glass lenses are fabricated in air, rather than in vacuum or inert atmospheres (e.g., $\mathrm{N}_{2}$ or Ar) to improve the productivity of glass lenses and to reduce manufacturing costs.

Figures 7(a) and (b) show XRD profiles of the synthesized $\mathrm{Ni}_{36} \mathrm{Nb}_{39} \mathrm{Zr}_{25}$ samples and the target $\mathrm{Ni}_{35} \mathrm{Nb}_{40} \mathrm{Zr}_{25}$ samples annealed at $723 \mathrm{~K}$ for various times in air, respectively. All the XRD profiles contain several sharp peaks due to the $\mathrm{Al}_{2} \mathrm{O}_{3}$ substrate. The 

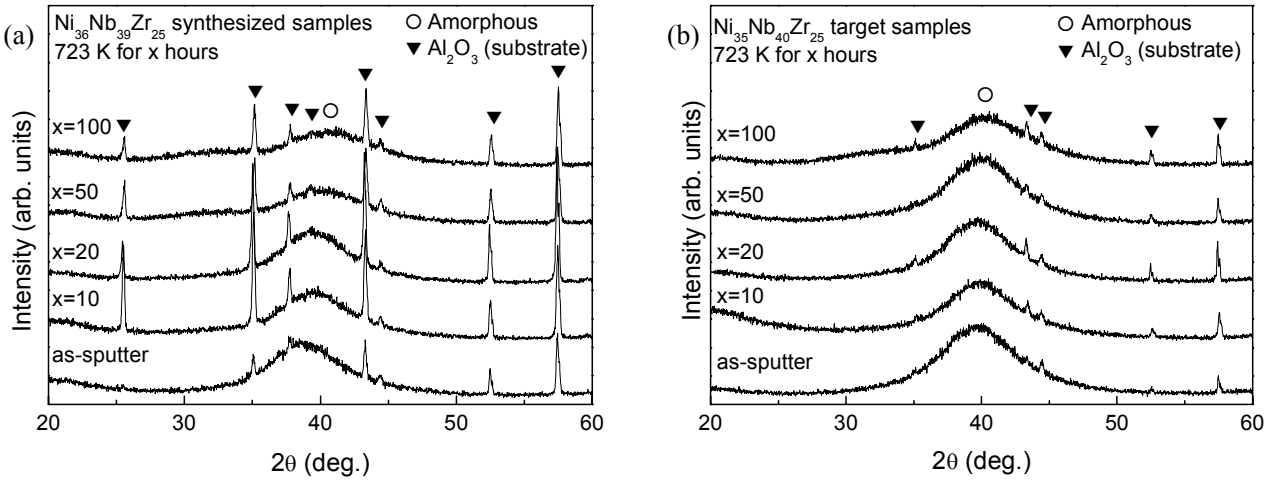

Fig. 6 XRD profiles of (a) synthesized and (b) target $\mathrm{Ni}-\mathrm{Nb}-\mathrm{Zr}$ samples annealed at $723 \mathrm{~K}$ for various times in vacuum
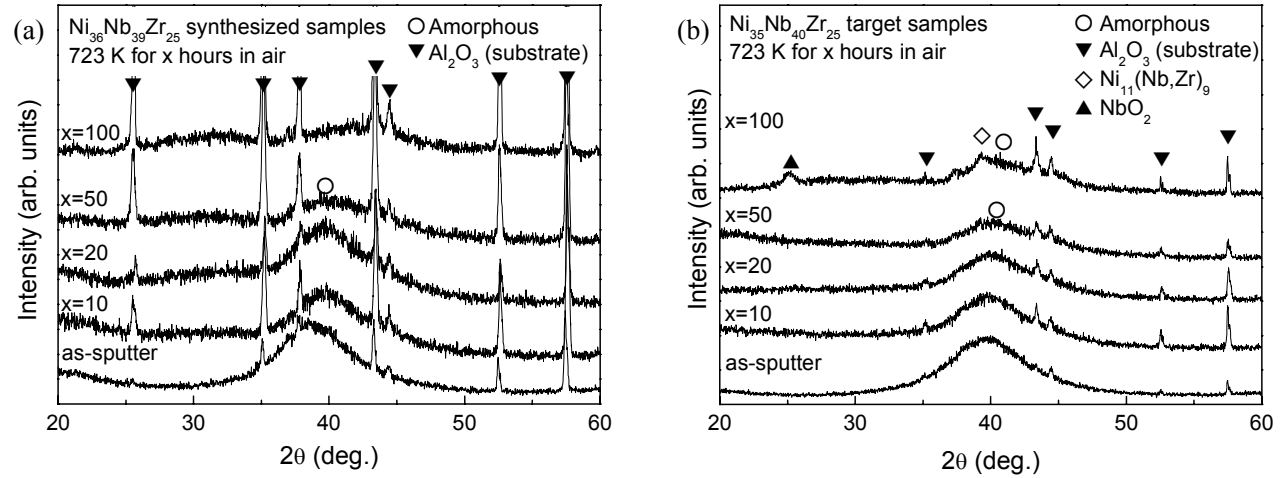

Fig. 7 XRD profiles of (a) synthesized and (b) target $\mathrm{Ni}-\mathrm{Nb}-\mathrm{Zr}$ samples annealed at $723 \mathrm{~K}$ for various times in air

synthesized samples (Fig. 7(a)) that were annealed for less than $50 \mathrm{~h}$ exhibited a halo pattern, which indicates that they are in the amorphous state. However, the intensity of the amorphous peak was weaker in the sample annealed for $50 \mathrm{~h}$. The sample annealed for $100 \mathrm{~h}$ showed two broad peaks at about $31^{\circ}$ and $42^{\circ}$. We could not identify these peaks, but it is considered that they are due to metallic oxides.

The target samples (Fig. 7(b)) that were annealed for less than $50 \mathrm{~h}$ also showed a halo pattern. However, the intensity of the amorphous peak in the sample annealed for 50 $\mathrm{h}$ was weaker. The sample annealed for $100 \mathrm{~h}$ showed peaks due to $\mathrm{Ni}_{11}(\mathrm{Nb}, \mathrm{Zr})_{9}$ and $\mathrm{NbO}_{2}$, in addition to the halo pattern.

To investigate the effect of annealing in vacuum and in air on the surface roughness, we used the white-light interferometer to measure the surface roughness $R_{a}$ of the annealed samples. Figure 8 shows the surface roughnesses $R_{a}$ of the annealed samples in vacuum and air. The as-sputtered target samples had an $R_{a}$ of $4.8 \mathrm{~nm}$, which is lower than

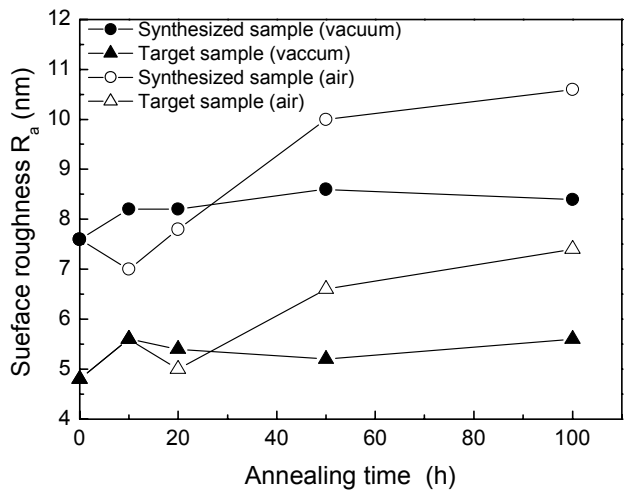

Fig. 8 Surface roughnesses of the annealed samples in vacuum and air 
that of the $\mathrm{Al}_{2} \mathrm{O}_{3}$ substrate $(6.0 \mathrm{~nm})$. In contrast, the as-sputtered synthesized samples had an $\mathrm{R}_{\mathrm{a}}$ of $7.6 \mathrm{~nm}$, which is greater than that of the $\mathrm{Al}_{2} \mathrm{O}_{3}$ substrate. The different $\mathrm{R}_{\mathrm{a}}$ of the both samples is discussed in section 3.5. The $R_{a}$ of both samples annealed for $10 \mathrm{~h}$ in vacuum was only slightly higher than that of the corresponding as-sputtered sample. This slight increase in the surface roughness might be caused by slight surface oxidization that was not detected by XRD measurements or by structural relaxation, such as residual stress relaxation or the filling of voids. In contrast, the $\mathrm{R}_{\mathrm{a}}$ of both samples annealed in vacuum varied little with increasing annealing time. Thus, these alloys exhibit a sufficiently high thermal stability of their amorphous states to be used as glass molding die materials. There was no detectable difference between the thermal stabilities of the amorphous states of the two samples.

On the other hand, the $\mathrm{R}_{\mathrm{a}}$ of both samples annealed in air increased slightly for annealing times less than $20 \mathrm{~h}$. The $\mathrm{R}_{\mathrm{a}}$ of the samples annealed for more than $50 \mathrm{~h}$ increased further and $\mathrm{R}_{\mathrm{a}}$ of the samples annealed for $100 \mathrm{~h}$ increased to $10.6 \mathrm{~nm}$ for synthesized samples, and $7.4 \mathrm{~nm}$ for target samples.

The effect of annealing time on $\mathrm{R}_{\mathrm{a}}$ is consistent with the XRD measurements. The $\mathrm{XRD}$ results reveal that none of the samples annealed in vacuum were obviously crystallized or oxidized. Consequently, there was only a slight change in $\mathrm{R}_{\mathrm{a}}$ on annealing. On the other hand, both samples annealed in air for less than $20 \mathrm{~h}$ showed only an amorphous peak in their XRD profiles. The $\mathrm{R}_{\mathrm{a}}$ of these samples is the similar to that of the as-sputtered samples. For both samples, the amorphous peak intensity decreases when the annealing time is $50 \mathrm{~h}$, which indicates that these samples were partially oxidized (although this was not detected by the XRD measurements). Thus, the surfaces of these samples became rough. On further annealing, the crystalline phase and/or metallic oxides appeared, making the surface rougher. These results imply that if molding dies for glass lenses are fabricated from these samples and are used in air their lifetimes might be less than $50 \mathrm{~h}$.

\subsection{Machinability}

Molding die materials require good machinabilities so that precise microstructures, such as diffraction gratings, can be fabricated on the optical surface of the molding die using a diamond cutting tool. Figures 9(a) and (b) show the cutting profile and surface roughness of the synthesized $\mathrm{Ni}_{36} \mathrm{Nb}_{39} \mathrm{Zr}_{25}$ sample, respectively. The synthesized samples could be cut into tapered shapes. The total cutting width in the radial direction was 0.88 $\mathrm{mm}$ and the total cutting depth in the axial direction was $0.62 \mu \mathrm{m}$. However, the actual cutting distance in the radial direction was shorter than the feed distance of $3 \mathrm{~mm}$. This is due to an error in setting the workpiece and a slight variation in the thickness of the amorphous alloy. These factors affected the cutting test results because the target cutting angle is very small $\left(5.73 \times 10^{-2} \mathrm{deg}\right.$ or $\left.1 \mathrm{~nm} / 1 \mu \mathrm{m}\right)$. The removal fraction $\mathrm{F}_{\mathrm{r}}$ of the synthesized sample was $70.5 \%$ (cutting depth/cutting width: $0.62 \mu \mathrm{m} / 0.88 \mathrm{~mm}$ ) and the $\mathrm{R}_{\mathrm{a}}$ of the cutting surface was $4.0 \mathrm{~nm}$.

Figures 10(a) and (b) show the cutting profile and the surface roughness of the target $\mathrm{Ni}_{35} \mathrm{Nb}_{40} \mathrm{Zr}_{25}$ sample, respectively. The target samples could also be cut into tapered shapes. The total cutting width in the radial direction was $2.24 \mathrm{~mm}$ and the total cutting depth in the axial direction was $2.15 \mu \mathrm{m} . \mathrm{F}_{\mathrm{r}}$ was $96.0 \%$ and $\mathrm{R}_{\mathrm{a}}$ was $4.0 \mathrm{~nm}$, which is equal to the $\mathrm{R}_{\mathrm{a}}$ of the synthesized sample. These results reveal that the target sample has a higher $F_{r}$ than the synthesized sample. The target sample exhibited excellent machinability.

\subsection{Different characteristics of the synthesized and target samples}

Comparing the characteristics of the synthesized and target samples reveals that both samples have similar thermal characteristics, including linear expansion coefficients, 

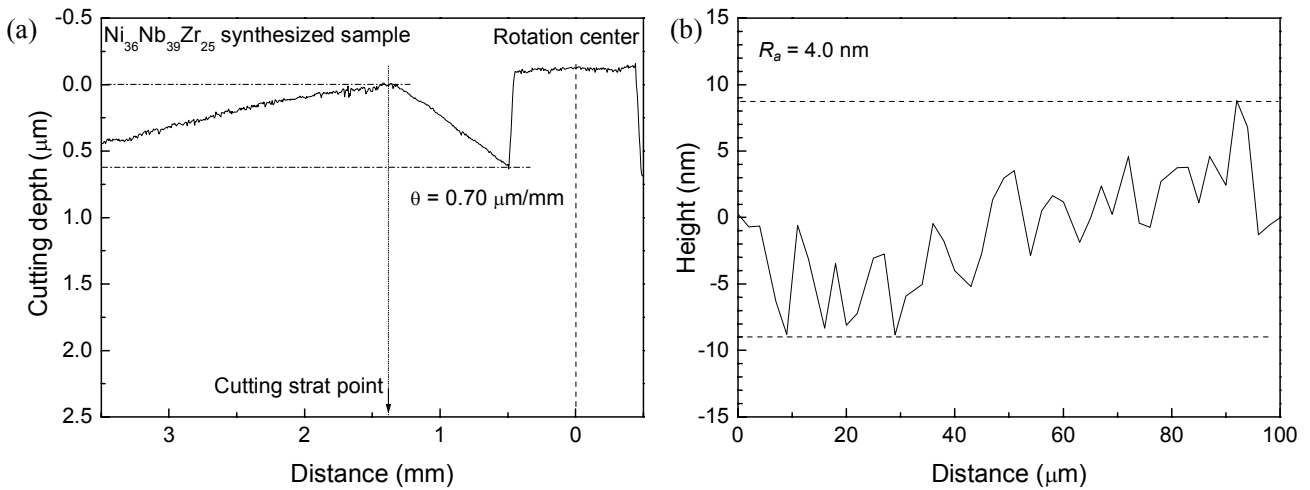

Fig. 9 (a) Cutting profile and (b) surface roughness of synthesized $\mathrm{Ni}_{36} \mathrm{Nb}_{39} \mathrm{Zr}_{25}$ sample
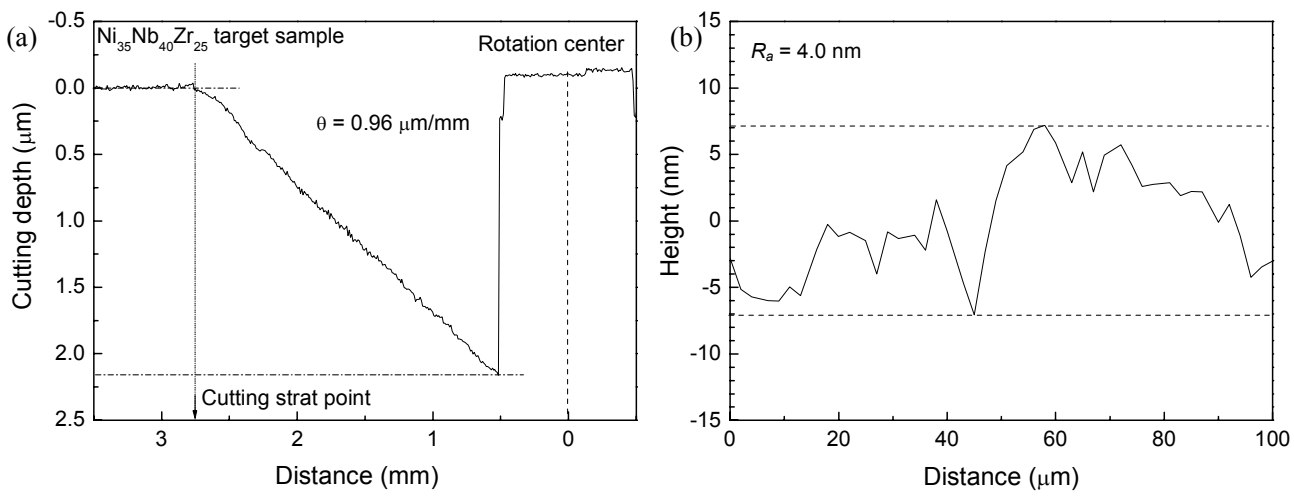

Fig. 10 (a) Cutting profile and (b) surface roughness of target $\mathrm{Ni}_{35} \mathrm{Nb}_{40} \mathrm{Zr}_{25}$ sample

thermal stabilities of their amorphous states, and oxidation resistances. On the other hand, they have different mechanical characteristics and machinabilities. These differences are considered to be caused by the configurations of the samples.

Figures 11(a) and (b) show SEM images of the surfaces of as-sputtered synthesized and target samples, respectively. Both samples exhibited grains. These grains are several micrometers in size. They are not crystalline grains but are traces of the crystalline grains of the $\mathrm{Al}_{2} \mathrm{O}_{3}$ substrate. The synthesized sample has a rough surface with many particles, which are less than $2 \mu \mathrm{m}$ in size. In contrast, the target sample has a smooth surface and with several dimples, which are about $0.5 \mu \mathrm{m}$ in size. This difference in the microstructures of the samples is considered to be responsible for the different surface roughnesses of the two as-sputtered samples (Fig. 8).

The microstructure of the synthesized sample corresponds to a columnar structure originating from sputter deposition at low sputtering rates caused by using a low RF power and a high Ar pressure ${ }^{(15)}$. In our previous study of Pt-based amorphous alloys, columnar
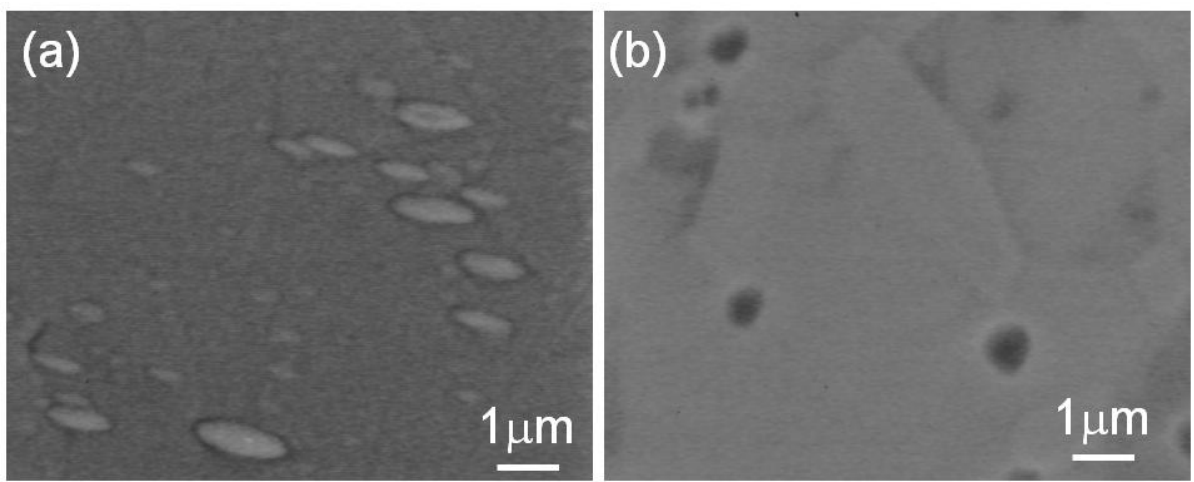

Fig. 11 SEM images of as-sputtered (a) synthesized and (b) target samples 
structures were much more obvious ${ }^{(10)}$. However, since the average RF powers of each target (shown in Table 1) used in the present study are larger than those in the previous study (e.g., the RF powers of the synthesized $\mathrm{Pt}_{50} \mathrm{Zr}_{36} \mathrm{Ni}_{14}$ sample were Pt: $100 \mathrm{~W}, \mathrm{Zr}$ : 200 $\mathrm{W}$, and $\mathrm{Ni}$ : $83 \mathrm{~W}^{(10)}$ ), columnar structures were not so obvious in the synthesized $\mathrm{Ni}_{36} \mathrm{Nb}_{39} \mathrm{Zr}_{25}$ sample. Since it is considered that the columnar structure is porous, the different microstructures of the two samples are expected to affect their mechanical properties more than their thermal characteristics. Thus, the synthesized sample has lower fracture stress and strain and hardness than the target sample. The difference in the Young's moduli of the two samples is caused by residual stress induced during sputtering as well as by the different microstructures, since the residual stress is affected by the sputtering conditions. Annealing has been reported to change the Young's modulus of a sputter-deposited amorphous alloy due to residual stress relaxation ${ }^{(16)}$.

Based on the machinability results, we conjecture that the machinabilities are affected by the microstructure in micro or nanomachining. We intend to investigate the effect of the sputtering conditions and microstructures on the machinabilities of thin-film amorphous alloys in future studies.

\subsection{Fabrication of molding die for glass lenses from amorphous $\mathrm{Ni}_{35} \mathrm{Nb}_{40} \mathrm{Zr}_{25}$ alloy}

We attempted to fabricate a molding die for glass lenses with diffraction gratings using amorphous $\mathrm{Ni}_{35} \mathrm{Nb}_{40} \mathrm{Zr}_{25}$ alloy. The amorphous $\mathrm{Ni}_{35} \mathrm{Nb}_{40} \mathrm{Zr}_{25}$ alloy was deposited on a blank STAVAX (Uddeholm) die that had been worked to an aspheric surface and was approximately $100 \mu \mathrm{m}$ thick. A glass lens mold was fabricated using an ultraprecision diamond machining system. Roughness machining was performed using a single-crystal diamond tool with a nose radius of $0.01 \mathrm{~mm}$, a rake angle of $0^{\circ}$, and a clearance angle of $5^{\circ}$. The workpiece was rotated at $100 \mathrm{rpm}$. The radial feed was $200 \mu \mathrm{m} / \mathrm{min}$ and the cutting depth was $1.0 \mu \mathrm{m}$. Final machining was performed using a sword-shaped single-crystal diamond tool with a clearance angle of $10^{\circ}$. The workpiece was rotated at $200 \mathrm{rpm}$. The radial feed was $100 \mu \mathrm{m} / \mathrm{min}$ and the cutting depth was $0.2 \mu \mathrm{m}$. The amorphous alloy was well adhered to the STAVAX substrate since the amorphous alloy did not peel off from the blank die during either machining process.

Figure 12(a) shows a photograph of a molding die for glass lenses and Figs. 12(b) and (c) show SEM images of the optical surface. This is molding die for a 5-mm-diameter pick-up lens. Figure 12(c) shows an SEM image of the periphery of diffraction gratings. Although the diffraction grating has been worked, tool marks are clearly visible on the optical surface. The surface roughnesses at the center and at the periphery of the optical surface are 4.9 and $14.9 \mathrm{~nm}$, respectively.

Figures 13 show images of a diamond cutting tool after (a) rough machining and (b) final machining. The dashed lines indicate the tool shape prior to machining. Edge rounding of the cutting tool disappeared after rough machining (Fig. 13(a)). Moreover, there were many weld deposits on the surface of the cutting tool and they were not removed by rough machining. On the other hand, the point of the cutting tool is chipped after final machining (Fig. 13(b)). Furthermore, there are also weld deposits on the cutting tool surface. Thus, although the roughness at the center of the surface is satisfactory for optical devices, the roughness at the outer periphery of the surface is too large because of tool chipping.

In the future, we intend to evaluate the machinabilities of actual length for fabricating a molding die for glass lenses. We will also determine appropriate cutting conditions for each material. Moreover, we intend to search for new $\mathrm{Ni}-\mathrm{Nb}$-based amorphous alloys that have better machinabilities. 

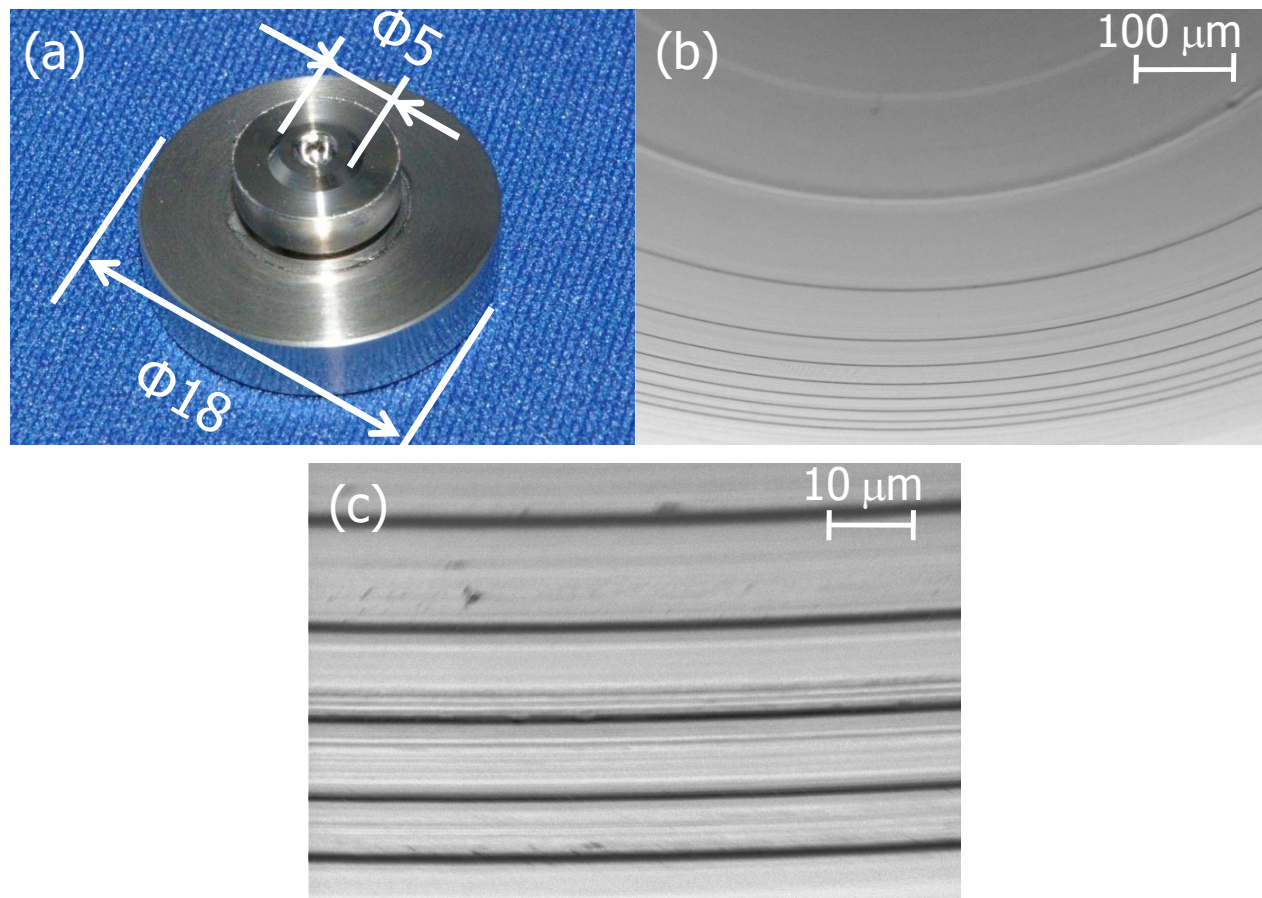

Fig. 12 (a) Photograph of a molding die for glass lenses and (b), (c) SEM images of the optical surface
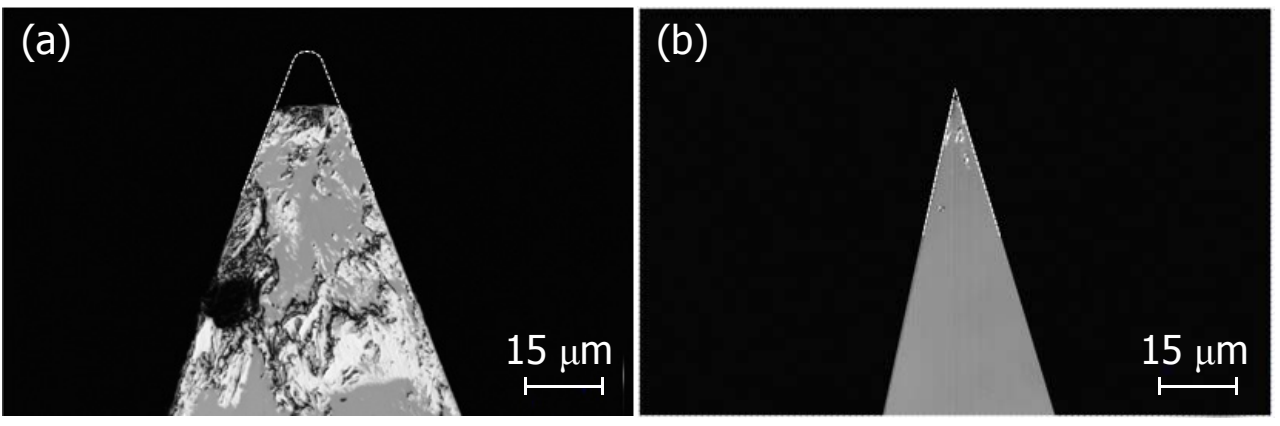

Fig. 13 SEM images of diamond cutting tools after (a) rough machining (rounding of the cutting tool ) and (b) final machining (point of the cutting tool)

\section{Conclusions}

We evaluated and compared the characteristics of synthesized and target $\mathrm{Ni}-\mathrm{Nb}-\mathrm{Zr}$ amorphous alloys to determine their suitability as molding die materials for high-precision optical glass lenses. The two samples exhibited no noticeable differences in their linear expansion coefficients, thermal stabilities of their amorphous states and oxidation resistances. On the other hand, they had different mechanical properties and machinabilities due to their different microstructure configurations. The target $\mathrm{Ni}_{35} \mathrm{Nb}_{40} \mathrm{Zr}_{25}$ sample exhibited excellent mechanical properties, including a high fracture stress and a high hardness, a similar linear expansion coefficient to that of BK7, an excellent thermal stability of amorphous state, an acceptable oxidation resistance, and high machinability. Finally, we fabricated an optical glass lens molding die with diffraction gratings made from amorphous $\mathrm{Ni}_{35} \mathrm{Nb}_{40} \mathrm{Zr}_{25}$ alloy. However, we need to clarify the following points:

1. The effect of the sputtering conditions and microstructures on the machinability of the amorphous alloys;

2. Determine suitable cutting conditions for each material;

3. Improve the machinability of $\mathrm{Ni}-\mathrm{Nb}$-based amorphous alloys by varying the third element if necessary. 


\section{Acknowledgment}

This research was supported by Grants-in-Aid for Young Scientists (B) (197604886) 2007-2008 and (S) (20676002) 2008-2012 from the Japan Society for the Promotion of Science (JSPS). Experiments were performed using equipment at the Installations for Nanomechatronics Research at the Tokyo Institute of Technology. We thank Konica Minolta Opto for assistance with the cutting tests and fabrication of the molding die for glass lenses.

\section{References}

(1) Yamamoto, Y., Suzuki, H., Onishi, T., Okino, T. and Moriwaki, T., Precision grinding of microarray lens molding die with 4-axes controlled microwheel, Science and Technology of Advanced Materials, Vol.8, No.3 (2007) pp.173-176.

(2) Fujii, T., Hirano, M., Shibukawa, T., Ishida, T., and Takeuchi, Y., Study on Precision Machining of Glass Lens Mold with Minute Structure, Journal of Japan Society of Precision Engineering Vol.74, No.12 (2008) pp.1298-1302 (in Japanese).

(3) Pramanik, A., Neo, K.S., Rahman, M., Li, X.P., Sawa, M., and Maeda, Y., Cutting performance of diamond tools during ultra-precision turning of electroless-nickel plated die materials, Journal of Materials Processing Technology, Vol.140, No.1-3, (2003) pp.308-313.

(4) Rahman, M., Lim, H. S., Neo, K.S., Kumar, A.S., Wong, Y. S., and Li, X.P., Tool-based nanofainishing and micromachining, Journal of Materials Processing Technology, Vol.185, No. 1-3 (2007) pp.2-16.

(5) Pramanik, A., Neo, K.S., Rahman, M., Li, X.P., Sawa, M., and Maeda, Y., Ultra-precision turning of electroless-nickel: Effect of phosphorus contents, depth-of-cut and rake angle, Journal of Materials Processing Technology, Vol.208, No.1-3 (2008) pp.400-408.

(6) Yan, J., Oowada, T., Zhou, T., and Kuriyagawa, T., Precision machining of microstructures on electroless-plated NiP surface for molding glass components, Journal of Materials Processing Technology, Vol.209, No.10 (2009) pp.4802-4808.

(7) Mekaru, H., Tsuchida, T., Uegaki, J., Yasui, M., Yamashita, M., and Takahashi, M., Micro lens imprinted on Pyrex glass by using amorphous Ni-P alloy mold, Microelectric Engineering, Vol.85, No.5-6, (2008) pp.873-876.

(8) Sakurai, J., Hata, S., Yamauchi, R., and Shimokohbe, A., Characterization of the Pt-Hf-Zr-Ni Thin Film Amorphous alloys for Precise Optical Glass Lens Mold, Journal of Solid Mechanocal Materials Engineering., Vol.3, No.8 (2009) pp.1022-1032.

(9) Keong, K.G., Sha, W., and Malinov, S., Crystallisation kinetics and phase transformation behavior of electroless nickel-phosphorus deposits with high phosphorus content, Journal of Alloys Compounds, Vol. 334, (2002) pp.192-199.

(10) Sakurai, J., Hata, S., Yamauchi, R., Abe, M., and Shimokohbe, A., Searching for Pt-Zr-Ni thin film amorphous alloys for optical glass lenses molding materials, Precision Engineering, Vol.34, No.3 (2010), pp.431-439.

(11) Sakurai, J., Abe, M., Ando, M., Aono, Y., and Hata, S., Searching for noble Ni-Nb-Zr thin film amorphous alloys for optical glass device molding die materials, Precision Engineering, (2010), in pressed

(12) Sakurai, J., Abe, M., Ando, M., and Hata, S., Combinatorial searching for Ni-Nb-Zr amorphous alloys as glass lens molding die materials, Key Engineering Materials., Vol. 447-448 (2010) pp.661-665.

(13) Sakurai, J., Hata, S., and Shimokohbe A., Characteristics of Cu-Zr Thin Film Metallic Glasses Fabricated by a Carousel-Type Sputtering System, Japanese Journal of Applied Physics, Vol.48, No.2 (2009) 025503 (6p)

(14) Schott AG "Data Sheet N-BK7" (online), available from 
$<\mathrm{http}: / /$ www.schott.com/advanced_optics/english/abbe_datasheets/datasheet_n-bk7.pdf $>$, (accessed 2010-9-13).

(15) Miyazaki, S., and Ishida, A., Martensitic transformation and shape memory behavior in sputter-deposited TiNi-base thin films, Materials Science and Engineering A, Vol. 273-275 (1999) pp.106-133.

(16) Hata, S., Liu, S., Wada, K., and Shimokohbe, A., Fabrication of thin film metallic glasses and their properties, Journal of Japan Society of Precision Enginnering ,Vol. 67, No.10 (2001) pp.1708-1713 (in Japanese). 